\title{
Sensitivity to Cognitive Effort Mediates Psychostimulant Effects on a Novel Rodent Cost/Benefit Decision-Making Task
}

\author{
Paul J Cocker ${ }^{1,2}$, Jay G Hosking*,1,2, James Benoit' and Catharine A Winstanley, \\ 'Department of Psychology, University of British Columbia, Vancouver, British Columbia, Canada
}

\begin{abstract}
Amotivational states and insufficient recruitment of mental effort have been observed in a variety of clinical populations, including depression, traumatic brain injury, post-traumatic stress disorder, and attention deficit hyperactivity disorder. Previous rodent models of effort-based decision making have utilized physical costs whereas human studies of effort are primarily cognitive in nature, and it is unclear whether the two types of effortful decision making are underpinned by the same neurobiological processes. We therefore designed a novel rat cognitive effort task (rCET) based on the 5-choice serial reaction time task, a well-validated measure of attention and impulsivity. Within each trial of the rCET, rats are given the choice between an easy or hard visuospatial discrimination, and successful hard trials are rewarded with double the number of sugar pellets. Similar to previous human studies, stable individual variation in choice behavior was observed, with 'workers' choosing hard trials significantly more than their 'slacker' counterparts. Whereas workers 'slacked off in response to administration of amphetamine and caffeine, slackers 'worked harder' under amphetamine, but not caffeine. Conversely, these stimulants increased motor impulsivity in all animals. Ethanol did not affect animals' choice but invigorated behavior. In sum, we have shown for the first time that rats are differentially sensitive to cognitive effort when making decisions, independent of other processes such as impulsivity, and these baseline differences can influence the cognitive response to psychostimulants. Such findings could inform our understanding of impairments in effort-based decision making and contribute to treatment development.

Neuropsychopharmacology (2012) 37, 1825-1837; doi:10.1038/npp.2012.30; published online 28 March 2012
\end{abstract}

Keywords: cognitive effort; cost/benefit decision making; individual differences; amphetamine; caffeine; rat

\section{INTRODUCTION}

Understanding the mechanism by which we come to prefer a particular option, and how different factors can influence that decision, is one of the overarching goals of both cognitive and behavioral neuroscience (Gold and Shadlen, 2007). There are typically a number of costs and benefits that must be evaluated when making a choice, including the probability of an event occurring, the time taken for it to occur, and the effort required to achieve success. Laboratory-based paradigms in which a particular factor within a decision frame (probability/delay/effort) is systematically varied have provided us with a wealth of information regarding the potential neurobiological systems implicated in different forms of decision-making (for a review, see Floresco et al, 2008a). By translating these tasks into nonhuman animal models, it is possible to test the causative relationships suggested by human data, and further

*Correspondence: JG Hosking or Dr CA Winstanley, Department of Psychology, University of British Columbia, 2136 West Mall, Vancouver, BC V6T IZ4, Canada, Tel: + I 604827 5083, Fax: + I 604822 6923, E-mail: jayhosking@psych.ubc.ca or cwinstanley@psych.ubc.ca

${ }^{2}$ These authors contributed equally to this work

Received 19 November 2011; revised 13 February 2012; accepted 17 February 2012 delineate the pharmacological and molecular regulation of the choice process (Chudasama and Robbins, 2006; Rushworth et al, 2011; Winstanley, 2011).

The degree of effort that we are willing to expend for a goal has far-reaching consequences for our economic and personal success. Animal models of such effort-based decision making have typically required animals to scale a barrier in a T-maze $v s$ traverse a flat runway, or press an operant lever a greater number of times, to receive a larger reward (Floresco et al, 2008c; Salamone et al, 1994). These studies have revealed key neural and neurochemical substrates involved in recruiting physical effort (Bardgett et al, 2009; Floresco and Ghods-Sharifi, 2007a; GhodsSharifi et al, 2009; Rudebeck et al, 2006; Salamone et al, 2007; Walton et al, 2003). However, most of the crucial decisions that determine success in an industrialized society involve varying degrees of cognitive, rather than physical, effort. For example, when deciding whether to perform the bare minimum at the office or to exceed expectations in the hope of promotion, one of the key costs we are evaluating is the cognitive effort required for the potentially more lucrative task. In human laboratory studies aimed at investigating the neurobiological basis of effort, the difficulty level is most often varied by increased cognitive demands such as attention or executive control (Botvinick et al, 2009; 
Croxson et al, 2009; McGuire and Botvinick, 2010; Naccache et al, 2005; but see Treadway et al, 2009). The nature of the effort exerted between most human and animal paradigms is therefore fundamentally different, and it is unclear whether the two types of effort-based decision making are underpinned by the same neurobiological processes (Kool et al, 2010; Kurniawan et al, 2011).

This is an important research question, as increases in mental fatigue, amotivational states, and insufficient recruitment of effort have been observed in a variety of clinical conditions, including depression (Cohen et al, 1982; Hammar et al, 2003; Hammar et al, 2011), mild traumatic brain injury (Stulemeijer et al, 2007; Stulemeijer et al, 2006), post-traumatic stress disorder (Shalev et al, 1990), attention deficit hyperactivity disorder (Egeland et al, 2010), and chronic fatigue syndrome (Lawrie et al, 1997; Wallman and Sacco, 2007). Such mental fatigue can produce physiological effects on the body (Mukherjee et al, 2011; Wright et al, 2003), negatively influence performance on unrelated cognitive processes (Wright et al, 2008), and time to recuperate is required following high cognitive effort (Barnes et al, 2009; Smit et al, 2004). The use of stimulants such as amphetamine and caffeine is a common strategy to overcome the mental fatigue associated with high attentional costs, such as sustained highway driving or university lecture attendance (Peeling and Dawson, 2007; Silber et al, 2006), although the extent of their beneficial effect is unclear (de Wit et al, 2002; Drummer et al, 2003). Conversely, depressants such as alcohol may have deleterious effects on cognitive tasks (de Wit et al, 2000; Field et al, 2010), but both stimulant and depressant effects can be strongly influenced by the individual differences between participants (Holdstock et al, 2000; Revelle et al, 1980; White et al, 2007).

In order to investigate whether rats are sensitive to differences in mental effort requirements when making decisions, we therefore designed a novel rat cognitive effort task (rCET) with costs more closely analogous to human studies, and conducted some pharmacological challenges to assess the task's utility for studying the neurobiology underlying this process. The rCET is a modification of the well-validated 5-choice serial reaction-time task (5CSRT), a rodent task originally modeled after the continuous performance test but akin to human reaction-time tasks that assess attention and impulsivity in clinical populations (Robbins, 2002). Within each trial of the rCET, rats are given the choice between an easy or hard visuospatial discrimination, and successful hard trials are rewarded with double the number of sugar pellets. We then evaluated the effects of amphetamine, caffeine, and alcohol on task performance to observe whether (a) stimulants could increase, or alcohol decrease, animals' willingness to choose the harder option, and (b) whether such changes were affected by basal levels of effortful choice, in accordance with reports in human subjects.

\section{MATERIALS AND METHODS}

\section{Subjects}

Subjects were 40 male long-evans rats (Charles River Laboratories, St Constant, Quebec, Canada) weighing 275$300 \mathrm{~g}$ at the start of the experiment, maintained at $85 \%$ of their free-feeding weight, and food restricted to $14 \mathrm{~g}$ rat chow per day. Water was available ad libitum. Animals were pair-housed in a climate-controlled colony room on a $12 \mathrm{~h}$ reverse light-dark cycle (lights off: $0800 \mathrm{~h}$; temperature: $21^{\circ} \mathrm{C}$ ). Housing and testing were in accordance with the Canadian Council of Animal Care, and all procedures were approved by the UBC Animal Care Committee.

\section{Behavioral Testing}

Testing took place within 16 standard five-hole operant chambers, each enclosed in a ventilated, sound-attenuating cabinet (Med Associates, Vermont, USA; see Winstanley, 2011, Supplementary Methods for details). The chambers were controlled by software written in Med-PC by CAW running on an IBM-compatible computer.

\section{Habituation and Pre-task Training}

Two 30-min habituation sessions preceded the training, wherein the response apertures and food magazine were baited with sucrose pellets. Animals subsequently learned to make a nose-poke response in an illuminated aperture within $5 \mathrm{~s}$ to obtain reward, as per 5CSRT training (Winstanley et al, 2003; Winstanley et al, 2010), before learning to respond on the left and right levers (see Supplementary Methods). Animals were then trained on a forced-choice variant of the rCET (55-60 sessions) before the full freechoice paradigm (see Supplementary Methods).

\section{The rCET}

Figure 1 depicts the rCET in schematic form. In all, 20 rats were trained to perform this task in two consecutive groups (group 1: $n=12$; group 2: $n=8$ ). At the outset, the levers were permanently designated to initiate either low-effort/ low-reward (LR) or high-effort/high-reward (HR) trials, and these designations were evenly counterbalanced across subjects.

Animals were required to nose poke at the food tray when the light inside was illuminated, thus initiating a trial and extending the levers. If one of the levers was pressed, thereby setting the trial as either LR or HR, both levers would retract and a 5-s inter-trial interval (ITI) would begin. Following the ITI, one of the five stimulus lights would be briefly illuminated, with a stimulus duration (SD) of $1.0 \mathrm{~s}$ for a LR trial and $0.2 \mathrm{~s}$ for a HR trial. Nose-poke responses in the illuminated hole led to a sugar rewardone pellet for a LR trial and two pellets for a HR trial-accompanied by illumination of the tray light and the opportunity to start the next trial.

There were a number of ways in which a trial went unrewarded: if animals failed to make a lever response within $10 \mathrm{~s}$ (a choice omission); if animals nose poked during the ITI (a premature response); if animals nose poked in any aperture other than the one that was illuminated (an incorrect response); and if animals failed to nose poke at the array within $5 \mathrm{~s}$ after stimulus light illumination (a response omission). All such behaviors were punished with a 5-s time-out period, signaled by illumination of the house light, during which reward could not be earned and new trials could not be initiated. At the end of this time-out period, 


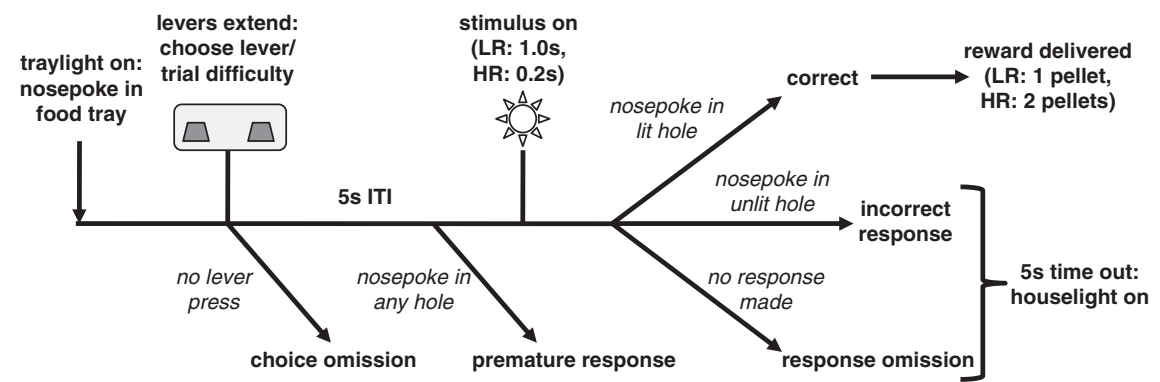

Figure I Schematic diagram showing the trial structure of the rCET. The task began with illumination of the tray light. A nose-poke response in the food tray extinguished the tray light, commencing a new trial and extending the levers. These levers were permanently designated to initiate either low-effort/LR or high-effort/HR trials. If one of the two levers was pressed, the levers retracted and a 5-s ITI would begin. Following the ITI, one of five stimulus lights would be briefly illuminated: $1.0 \mathrm{~s}$ for a LR trial and $0.2 \mathrm{~s}$ for a HR trial. A nose-poke response in the illuminated hole (ie, correct response) led to a sugar reward — one pellet for a LR trial and two pellets for a HR trial — and the tray light would illuminate, indicating the opportunity to start the subsequent trial. A number of behaviors led to a 5-s time-out, signaled by house-light illumination: failure to make a lever response (choice omission); failure to withhold responding during the ITI (premature response); nose poke in an unlit hole following the stimulus (incorrect response); failure to make a nose-poke response following the stimulus (response omission).

the tray light was illuminated to signal that the rat could begin the next trial.

Animals were trained 5 days per week in 30-min sessions of no fixed trial number. Training continued until a stable level of baseline performance was observed (19-25 sessions).

\section{The Yoked Control Task}

In order to determine whether choice in the rCET was driven by the allocation of cognitive effort or sensitivity to differential rates of reinforcement, a second cohort $(n=20)$ was trained to perform a control task in which the reinforcement probabilities on both the LR and HR trials depended on a master animal's performance on the rCET. The average accuracy on LR and HR trials was calculated for each rat performing the $\mathrm{rCET}$ at baseline, and these accuracies were used to determine the reward schedule for a yoked control rat. The structure of the control task was identical to that of the rCET, with the exception that the stimulus light remained illuminated until the rat made a response.

As in the rCET, rats were trained to perform the yoked control task in two consecutive groups (group 1: $n=12$; group 2: $n=8$ ). The habituation and pre-training phases for the control task were identical to those used for the rCET. The animals were then placed on a forced choice variant of the yoked control task for 10 sessions, wherein only one of the two levers extended per trial, before moving onto the free choice version. Control sessions lasted $30 \mathrm{~min}$. Training continued until a stable level of baseline performance was observed (29-35 sessions).

\section{Behavioral Measurements}

Percent choice, rather than the absolute number of choices, was used to determine preference for lever/trial type in order to minimize the influence of variation in the number of trials completed when analyzing differences in choice preference. Percent choice was calculated as follows: (number of choices of a particular lever/number of total choices) $\times$ 100. The following variables were also analyzed separately for LR and HR trials: accuracy ((number of correct responses/ number of total responses made $\times 100$ ); response omissions ((number of trials omitted/number of correct, incorrect and omitted trials $) \times 100)$; premature responses ((number of premature responses/total number of trials initiated) $\times 100)$; latency to choose between the LR/HR levers (lever choice latency), latency to correctly nose poke in the illuminated aperture (correct latency), and latency to collect reward (collection latency). Failures to choose a lever at the beginning of a trial (choice omissions) and the total number of trials completed were also analyzed.

\section{Pharmacological Challenges}

Once stable baseline behavior had been established, drugs were administered in the following order: amphetamine $(0,0.3,0.6$, $1.0 \mathrm{mg} / \mathrm{kg}$; Sun et al, 2012), ethanol (0, 0.3, 0.6, $1.0 \mathrm{~g} / \mathrm{kg}$; Bizarro et al, 2003), and caffeine $(0,5,10,20 \mathrm{mg} / \mathrm{kg}$; Bizarro et al, 2004). $d$-amphetamine sulfate was purchased under a Health Canada exemption from Sigma-Aldrich, UK (Dorset, England), caffeine was purchased from SigmaAldrich Canada (Oakville, ON, Canada), and ethyl alcohol was purchased from Fisher Scientific (Edmonton, AB, Canada). All drugs were administered via intraperitoneal injection. Amphetamine and caffeine were dissolved in $0.9 \%$ sterile saline and administered in a volume of $1 \mathrm{ml} / \mathrm{kg}$, and alcohol was delivered as a $20 \%(\mathrm{w} / \mathrm{v})$ solution. Animals were given a minimum of 1 week drug-free testing between compounds to minimize any carryover effects.

All drugs were prepared fresh daily, and administration adhered to a digram-balanced Latin Square design (for doses A-D: ABCD, BDAC, CABD, DCBA (p 329, Cardinal and Aitken, 2006)). The injection schedule followed a 3-day cycle starting with a baseline session, followed by a drug or saline injection session, and then by a non-testing day. Injections were administered $10 \mathrm{~min}$ before behavioral testing for amphetamine and caffeine, and $30 \mathrm{~min}$ before behavioral testing for ethanol.

\section{Acute and Chronic Satiation}

Following 1 week of drug-free testing, half of the animals were given unlimited access to food for $2 \mathrm{~h}$ before testing 
(acute satiation (AS)). The other half of the animals was tested under food restriction (FR) as per usual. A non-testing day and baseline (ie, FR) session followed. During the next testing day, the other half of the animals underwent AS before testing whereas the first half remained FR. Immediately after this second session of AS, free feeding began for all animals, wherein food was provided ad libitum. Two nontesting days were followed by five daily sessions during this chronic satiation (CS) period.

\section{Data Analysis}

All data were analyzed in SPSS (version 16.0; SPSS/IBM, Chicago, IL, USA). Any variables expressed as a percentage were arcsine transformed to minimize artificial ceiling effects (Winstanley et al, 2003; Zeeb et al, 2009). Baseline data were analyzed using within-subjects repeated-measures ANOVA with choice (two levels: LR or HR) and session (five levels: baseline sessions 1-5) as repeated measures factors. Animals' baseline behavior was deemed stable if there was no main effect of session for all recorded measurements. One animal failed to establish stable behavior and was thus removed from the analyses, as was its control counterpart. Once behavior had stabilized, the mean choice of the HR option was $70-71 \%$. Animals were thus grouped as 'workers' if they chose HR for $>70 \%$ of trials $(n=11)$ and as 'slackers' if they chose HR for $\leqslant 70 \%$ of trials $(n=8)$. Group (two levels: worker or slacker) was therefore used as a between-subjects factor in all analyses. Groups proved remarkably stable across the experiment: at baseline, all saline conditions for drug challenges, and FR during satiation manipulation, workers chose a significantly greater percentage of HR trials (group: all F's $>8.93$, all $p<0.008$ ). Additionally, each animal's baseline and CS sessions were divided into quartiles, with equal numbers of trials in each quartile, and HR choice was examined across the session using Quartile (four levels: Q1-Q4) as a repeated-measures factor.

The effects of pharmacological challenges and satiation were again analyzed using within-subjects repeated-measures ANOVA. For drug challenges, dose (four levels: saline plus three drug doses) and choice were included as repeatedmeasures factors, with group as a between-subjects factor. For satiation, condition (three levels: FR, AS, or CS) and choice were within-subjects factors, whereas group was a between-subjects factor. Any main effects of significance $(p<0.05)$ were further analyzed via post-hoc one-way ANOVA or paired-samples $t$-tests between vehicle and drug, or workers and slackers. Any $p$-values $>0.05$ but $<0.075$ were reported as a statistical trend.

\section{RESULTS}

\section{Baseline Performance of the rCET}

Choice behavior, accuracy, and premature responses. When considered as a homogenous group, animals chose high-effort/HR trials more than low-effort/LR trials (choice: $\mathrm{F}_{1,17}=82.06, p<0.001$ ), although there was clearly a continuum of individual variation across the cohort. When the animals were divided into two groups depending on whether they were above or below the mean choice of the HR option (see materials and methods), individuals above the mean ('workers') chose HR trials significantly more than individuals below the mean ('slackers') (Figure 2a; group: $\mathrm{F}_{1,17}=$ $27.94, p<0.001)$. When the session was divided by quartiles of equal trial number, all animals chose more HR trials as the session progressed (Supplementary Figure S1; quartile: $\mathrm{F}_{3,51}=22.84, p<0.001$; quartile $\times$ group: $\mathrm{F}_{3,51}=2.94, \mathrm{NS}$ ). All animals were significantly more accurate for LR trials than for HR trials (Figure 2b; choice: $F_{1,17}=167.28, p<0.001$ ), regardless of whether they were workers or slackers (choice $\times$ group: $F_{1,17}=0.20, N S$ ). However, both workers and slackers performed equally well on LR and HR trials (group: $\mathrm{F}_{1,17}=0.18$, NS) despite workers choosing HR trials more often, suggesting that preference for the HR trials was not driven solely by attentional ability. Premature responding was higher during HR vs LR trials (Figure 2c; choice: $\mathrm{F}_{1,17}=16.97, p=0.001$ ), but there were no significant differences in premature responding between workers and slackers (choice $\times$ group: $F_{1,17}=0.15$, NS; group: $F_{1,17}=2.33, \mathrm{NS}$ ) .

Other behavioral measures. Animals took the same amount of time to choose LR trials as they did for HR trials (choice: $\mathrm{F}_{1,17}=1.27, \mathrm{NS}$ ), and there were no significant differences in this lever choice latency for workers $v s$ slackers (choice $\times$ group: $F_{1,17}=0.56, \mathrm{NS}$; group: $\mathrm{F}_{1,17}=1.77$, NS; see Supplementary Table S1). Perhaps unsurprisingly, given the shorter $\mathrm{SD}$, animals were quicker to perform a correct response at the array during HR trials as compared with LR trials (choice: $\mathrm{F}_{1,17}=20.96, p<0.001$ ) but this did not differ between workers and slackers (choice $\times$ group: $F_{1,17}=0.60, \quad N S$; group: $\mathrm{F}_{1,17}=0.02$, NS). Animals were quicker to collect reward on successful HR trials than for successful LR trials (choice: $\mathrm{F}_{1,17}=5.55, \quad p=0.031 ;$ choice $\times$ group: $\mathrm{F}_{1,17}=0.63, \mathrm{NS}$ ) . However, a main effect of group was observed on this measure (group: $\mathrm{F}_{1,17}=4.84, p=0.042$ ) and a closer examination showed that only slackers were faster to collect their reward on HR trials (choice-slackers only: $F_{1,7}=6.59$, $p=0.037$; -workers only: $\mathrm{F}_{1,10}=1.16$, NS). Furthermore, workers and slackers collected equally fast on LR trials (group-LR trials only: $\mathrm{F}_{1,17}=2.52$, NS) but slackers collected faster for HR trials as compared with workers (group-HR trials only: $F_{1,17}=5.62, p=0.030$ ). Altogether, these data suggest that slackers anticipated a larger reward following successful completion of more difficult (HR) trials, but still chose fewer of these trials than their worker counterparts. Both groups of rats made the same percentage of nose-poke response omissions for both LR and HR trials (choice: $\mathrm{F}_{1,17}=0.01, \mathrm{NS}$; choice $\times$ group: $\mathrm{F}_{1,17}=0.01, \mathrm{NS}$; group: $\mathrm{F}_{1,17}=0.10$, NS), the same number of choice omissions (group: $\mathrm{F}_{1,17}=1.18, \mathrm{NS}$ ), and completed the same number of trials per session (group: $\mathrm{F}_{1,17}<0.01, \mathrm{NS}$ ).

\section{Effect of d-Amphetamine Administration on Performance of the rCET}

Choice behavior, accuracy, and premature responses. Amphetamine differentially affected preference for HR trials in workers and slackers (Figure 3a and Supplementary Figure S2; dose: $\mathrm{F}_{3,51}=0.94$, NS; dose $\times$ group: $\mathrm{F}_{3,51}=3.76$, $p=0.016$ ). Workers chose significantly more HR trials than slackers when saline or $0.3 \mathrm{mg} / \mathrm{kg}$ amphetamine was administered (group-saline: $\mathrm{F}_{1,17}=66.22, p<0.001 ;-0.3 \mathrm{mg} / \mathrm{kg}$ : $\mathrm{F}_{1,17}=14.03, p=0.002$ ) but choice behavior for workers and 

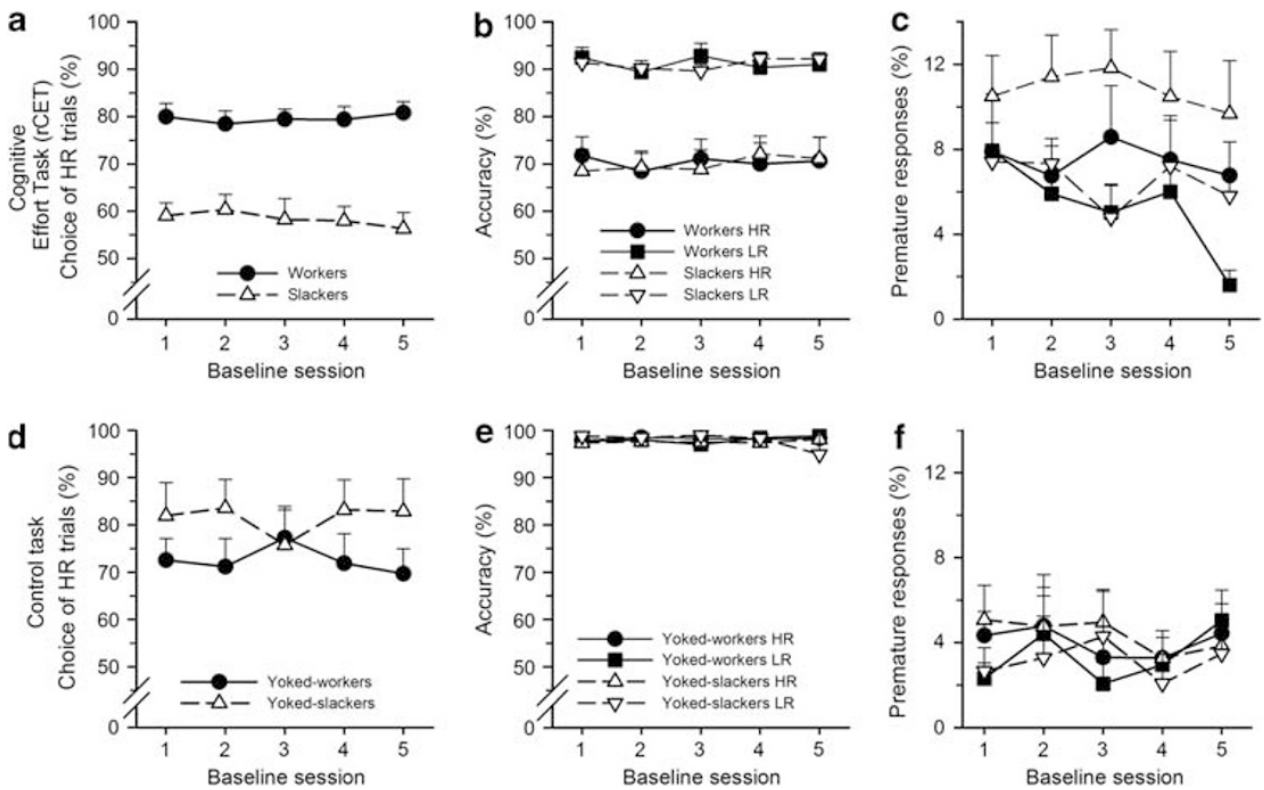

Figure 2 Baseline behavior on the rCET and control task. (a) All animals showed a preference for high-effort/HR trials (choice: $p<0.00 \mathrm{I}$ ), but there was considerable individual variation in choice: animals above the mean for HR choice ('workers') chose HR trials significantly more than animals below the mean ('slackers'; group: $p<0.00 \mathrm{I}$ ). (b) Despite differences in choice, workers and slackers performed equally well on both low-effort/LR and HR trials. Accuracy was significantly lower for HR vs LR trials (choice: $p<0.00 \mathrm{I}$ ). (c) All animals exhibited greater premature responding for $H R$ vs $L R$ trials (choice: $p=0.00 \mathrm{I}$ ), and no significant differences between workers and slackers were observed for this measure of motor impulsivity. (d) When cognitive effort costs were removed and control animals were yoked to experimental animals' rates of reinforcement (ie, accuracy), control animals preferred the normatively favorable HR trials (choice: $p<0.00 \mathrm{I}$ ). Unlike the rCET, however, no significant differences in choice were observed for yoked-workers vs yoked-slackers. (e) All control animals were nominally more accurate for LR vs HR trials (choice: $p=0.048$ ), although accuracy was above $97 \%$ for both trial types. (f) For all control animals, premature responding was higher for HR vs LR trials (choice: $p=0.017$ ). Data are shown as the mean percent choice for each option ( \pm SEM).

slackers was indistinguishable after 0.6 and $1.0 \mathrm{mg} / \mathrm{kg}$ (group $-0.6 \mathrm{mg} / \mathrm{kg}: \mathrm{F}_{1,17}=2.70, \mathrm{NS} ;-1.0 \mathrm{mg} / \mathrm{kg}$ : $\mathrm{F}_{1,17}=$ 0.056 , NS), as the preference for $\mathrm{HR}$ trials decreased in workers and increased in slackers. Amphetamine also had some minor effects on accuracy of target detection (Figure $3 b$ ), slightly decreasing workers' accuracy on HR trials at $0.6 \mathrm{mg} /$ $\mathrm{kg}$ (choice $\times$ dose $\times$ group: $\mathrm{F}_{3,51}=4.84, p=0.005$; workers only-choice $\times$ dose: $\mathrm{F}_{3,30}=2.68, p=0.065$; dose-HR trials only: $\mathrm{F}_{3,30}=4.97, p=0.026$; saline $v s \quad 0.6 \mathrm{mg} / \mathrm{kg}$ : $\left.\mathrm{F}_{1,10}=6.16, p=0.032\right)$. Amphetamine also tended to affect accuracy in slackers (slackers only-dose $\times$ choice: $F_{3,21}=$ 3.07, $p=0.050$ ), but when slackers' LR and HR trials were considered independently, no effects on accuracy were observed (all F's $<2.365$, NS). In keeping with previous reports, amphetamine dose-dependently increased premature responding in all animals (Figure $3 \mathrm{c}$; dose: $\mathrm{F}_{3,51}=5.55$, $p=0.008$; group: $\left.\mathrm{F}_{3,51}=0.69, \mathrm{NS}\right)$.

Other behavioral measures. Amphetamine had no effect on any response or reward collection latencies (all F's $<2.29$, NS) but dose-dependently increased the number of choice omissions (dose: $\mathrm{F}_{3,51}=7.81, p<0.001$ ) and decreased the number of completed trials (dose: $\mathrm{F}_{3,51}=6.65, p=0.001$; see Supplementary Table S2). Response omissions were differentially affected by amphetamine (dose: $F_{3,51}=1.90$, NS; dose $\times$ choice: $\left.\mathrm{F}_{3,51}=4.87, p=0.012\right)$ : the intermediate dose increased nose-poke omissions for HR trials whereas the highest dose decreased response omissions for LR trials (dose-LR trials only: $\mathrm{F}_{3,51}=2.97, p=0.065$; saline $v s$
$1.0 \mathrm{mg} / \mathrm{kg}: \mathrm{F}_{1,17}=9.26, p=0.007$; HR trials only: $\mathrm{F}_{3,51}=$ 3.13, $p=0.058$; saline vs $0.6 \mathrm{mg} / \mathrm{kg}: \mathrm{F}_{1,17}=7.32, p=0.015$ ) These effects were not related to animals' classification as workers or slackers (dose $\times$ group/dose $\times$ choice $\times$ group: all F's $<0.88$, NS).

\section{Effect of Ethanol Administration on Performance of the rCET}

Choice behavior, accuracy, and premature responses. Ethanol had no effects on choice behavior, accuracy, or premature responses in either workers or slackers (Figure $3 \mathrm{~d}-\mathrm{f}$; all F's $<1.81$, NS).

Other behavioral measures. There was a trend for ethanol to dose-dependently speed lever choice latency regardless of which choice the animals made or their relative preference for $\mathrm{HR}$ trials (dose: $\mathrm{F}_{3,51}=3.00, p=0.066$; . dose $\times$ choice: $\mathrm{F}_{3,51}=0.68$, NS; group: $\mathrm{F}_{3,51}=0.43$, NS; see Supplementary Table S3). Ethanol also dose-dependently decreased the correct latency for $\mathrm{HR}$ trials in all rats (dose $\times$ choice: $\mathrm{F}_{3,51}=3.93, p=0.013$; dose $-\mathrm{HR}$ trials only: $\mathrm{F}_{3,51}=3.32$, $p=0.027$; saline $\left.v s 0.6 \mathrm{~g} / \mathrm{kg}: \mathrm{F}_{1,17}=4.60, p=0.047\right)$. Ethanol had no effect on collection latency (dose: $F_{3,51}=0.81$, NS) or choice omissions (dose: $\mathrm{F}_{3,51}=3.13$, NS) but decreased response omissions for $\mathrm{LR}$ trials (dose $\times$ choice: $\mathrm{F}_{3,51}=$ 6.92, $p=0.006$; LR trials only: $\mathrm{F}_{3,51}=3.60, p=0.020$; saline vs $0.3 \mathrm{~g} / \mathrm{kg}: \mathrm{F}_{1,17}=5.62, p=0.030$; saline vs $0.6 \mathrm{~g} / \mathrm{kg}: \mathrm{F}_{1,17}=$ 5.21, $p=0.036$; dose - HR trials only: $\mathrm{F}_{3,51}=2.32$, NS) and 

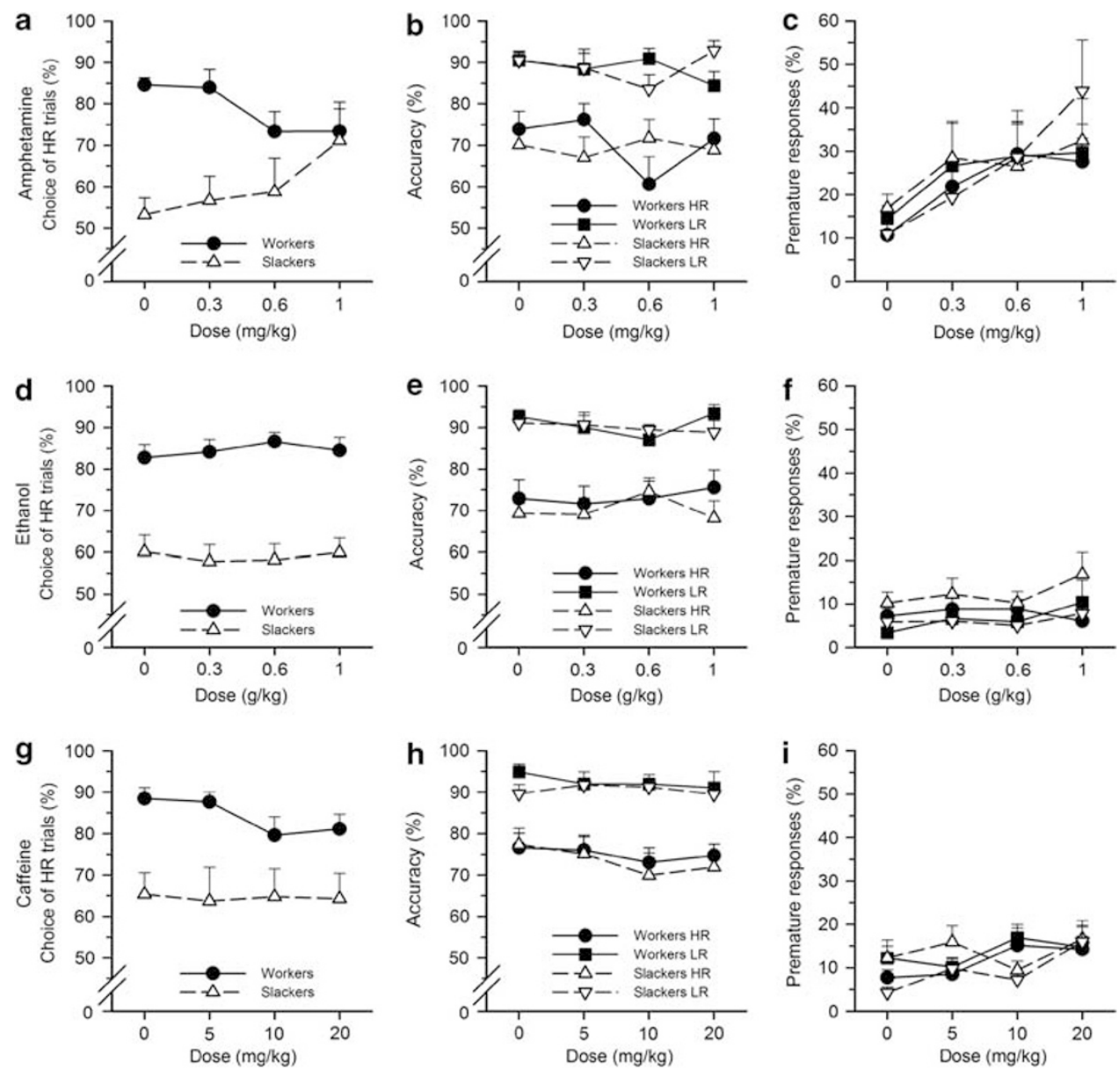

Figure 3 Pharmacological manipulation of cognitive effort is dissociated from visuospatial attention and motor impulsivity. (a) $d$-amphetamine significantly attenuated the heterogeneity of choice behavior, making workers 'slack off and slackers 'work harder' (dose $\times$ group: $p=0.0$ l6). Choice behavior for workers and slackers was significantly different at saline and $0.3 \mathrm{mg} / \mathrm{kg}$ (group: all $p<0.002$ ) but indistinguishable after 0.6 and $1.0 \mathrm{mg} / \mathrm{kg}$. (b) Although mild impairments of accuracy were observed for workers' high-effort $/ \mathrm{HR}$ trials at $0.6 \mathrm{mg} / \mathrm{kg}(p=0.032)$, amphetamine had no main effect on accuracy for all animals. (c) Despite amphetamine's opposing effects on the choice behavior of workers and slackers, the psychostimulant significantly increased motor impulsivity for all animals in both trial types (dose: $p=0.008)$. ( $(-f)$ Ethanol had no effects on choice, accuracy, or premature responding for all animals. (g) Caffeine reduced workers' choice of HR trials (dose: $p=0.008$ ) but had no effect on slackers' choice behavior. (h) Caffeine had no effects on accuracy for all animals. (i) Caffeine modestly increased premature responding for all animals when both trial types were considered together (dose: $p=0.029$ ). Data are shown as the mean percent choice for each option $( \pm$ SEM).

increased the number of trials completed (dose: $\mathrm{F}_{3,51}=3.81$, $p=0.015 ;$ saline $\left.v s 0.6 \mathrm{mg} / \mathrm{kg}: \mathrm{F}_{1,17}=7.27, p=0.015\right)$. The classification of animals as workers or slackers did not significantly interact with the effects of ethanol for any recorded measures (dose $\times$ group/dose $\times$ choice $\times$ group: all F's $<2.54$, NS).

\section{Effect of Caffeine Administration on Performance of the rCET}

Choice behavior, accuracy, and premature responses. When considered as a homogenous group, caffeine had no main effect on choice behavior (dose: $\mathrm{F}_{3,51}=2.24$, NS), although group differences in choice remained (group: $\mathrm{F}_{1,17}=10.30, \quad p=0.005$ ). Subsequent inspection of the reaction to caffeine in each group revealed that the higher doses of caffeine decreased choice of HR trials in workers (Figure 3g; workers only-dose: $\mathrm{F}_{3,30}=4.70, p=0.008$; saline $v s 10 \mathrm{mg} / \mathrm{kg}: \mathrm{F}_{1,10}=6.56, p=0.028$; saline $v s 20 \mathrm{mg} / \mathrm{kg}$ :
$\left.\mathrm{F}_{1,10}=4.69, p=0.056\right)$. In contrast, the drug had no effect on choice behavior in slackers (slackers only-dose: $\mathrm{F}_{3,21}=0.01$, NS). Caffeine had no effects on accuracy in either group (Figure 3 h; dose: $F_{3,51}=1.16$, NS; dose $\times$ group: $\mathrm{F}_{3,51}=0.35$, NS) but dose-dependently increased premature responding (Figure 3i; dose: $\mathrm{F}_{3,51}=3.26, p=0.029$ ). This effect tended to be more evident in slackers (dose $\times$ group: $\mathrm{F}_{3,51}=2.51, p=0.069$; dose - workers only: $\mathrm{F}_{3,30}=2.43$, NS; slackers only: $\mathrm{F}_{3,21}=7.06, p=0.033$; dose $\times$ choice: $\mathrm{F}_{3,21}=$ 7.52, $p=0.001)$. In this group, the increase in impulsive responding was also most evident during LR trials (choice $\times$ dose: $F_{3,21}=7.52, p=0.001$; dose - LR trials only: $F_{3,21}=$ 7.18, $p=0.002$; HR trials: $\mathrm{F}_{3,21}=2.74, p=0.069$ ).

Other behavioral measures. Caffeine significantly speeded up choice of the LR option, without affecting the time taken to choose the HR lever (dose: $\mathrm{F}_{3,51}=3.13, p=0.034$; dose $\times$ choice: $\mathrm{F}_{3,51}=3.70, p=0.017$; dose $-\mathrm{HR}$ trials only: $\mathrm{F}_{3,51}=0.95, \mathrm{NS} ; \mathrm{LR}$ trials only: $\mathrm{F}_{3,51}=4.49, p=0.007$; 
saline vs $5 \mathrm{mg} / \mathrm{kg}: \mathrm{F}_{1,17}=11.37, p=0.004$; saline vs $20 \mathrm{mg} / \mathrm{kg}$ : $\mathrm{F}_{1,17}=12.16, p=0.003$; see Supplementary Table S4). In contrast, caffeine had no effect on either the correct latency, collection latency, or choice omissions (all F's $<1.90$, NS), but tended to increase response omissions for both trial types (dose: $F_{3,51}=2.57, p=0.064$ ) and decreased the number of trials completed (dose: $\mathrm{F}_{3,51}=5.14, p=0.004$; saline vs $\left.20 \mathrm{mg} / \mathrm{kg}: \mathrm{F}_{1,17}=6.34, p=0.022\right)$. No significant interactions with group were observed in any of these analyses (dose $\times$ group/dose $\times$ choice $\times$ group: all F's $<2.06$, NS).

\section{Effect of Satiation on Performance of the rCET}

Choice behavior, accuracy, and premature responses. Satiation significantly decreased the choice of HR trials for all animals, regardless of whether they were workers or slackers (Figure 5a; condition: $\mathrm{F}_{2,34}=13.58, p<0.001$; condition $\times$ group: $\mathrm{F}_{2,34}=1.52$, NS). As compared with $\mathrm{FR}$, choice of HR trials was significantly lower at CS but not for AS (condition-FR vs CS: $\mathrm{F}_{1,17}=29.08, p<0.001$; FR vs AS: $\left.\mathrm{F}_{1,17}=2.97, \mathrm{NS}\right)$. Similarly, animals chose HR trials significantly less for CS than for AS (condition-AS vs CS: $\mathrm{F}_{1,17}=$ $11.10, p=0.004)$. However, workers and slackers maintained their categorical distinction, with workers choosing HR trials significantly more than slackers (group: $\mathrm{F}_{1,17}=11.52$, $p=0.003$ ). Additionally, CS eliminated the progressive increase of HR trials across the session (quartile: $F_{3,51}=1.79$, NS). Satiation decreased accuracy across all animals and trial types (Figure 5b; condition: $\mathrm{F}_{2,34}=15.68, p<0.001$; condition $\times$ group: $F_{2,34}=0.82$, NS; choice $\times$ condition: $F_{2,34}=$ 0.20 , NS), but did not affect premature responding (Figure $5 \mathrm{c}$; condition: $\mathrm{F}_{2,34}=2.39$, NS; condition $\times$ group: $\left.\mathrm{F}_{2,34}=0.27, \mathrm{NS}\right)$.

Other behavioral measures. All response and collection latencies were increased by satiation (condition: all F's $>6.04$, all $p<0.006$; see Supplementary Table S5). Although correct latency was increased for both trial types (condition-LR trials only: $\mathrm{F}_{2,34}=15.98, p<0.001$; HR trials only: $\left.F_{2,34}=9.03, p=0.002\right)$, this latency was longer for $L R$ vs $\mathrm{HR}$ trials at AS (LR $v s \mathrm{HR}$, AS: $t=2.89$, d.f. $=18, p=$ $0.010)$ and CS (LR $v s$ HR, CS: $t=2.94$,d.f. $=18, p=0.009$ ) but not at FR (LR $v s$ HR, FR: $t=1.08$, d.f. $=18$, NS). Satiation increased choice omissions (condition: $\mathrm{F}_{2,34}=5.75$, $p=0.007$ ), increased response omissions (condition: $\mathrm{F}_{2,34}=62.58, p<0.001$ ), and decreased the number of completed trials (condition: $\mathrm{F}_{2,34}=89.43, p<0.001$ ) for all animals. No interaction with group was observed for any of the above recorded measures (condition $\times$ group/condition $\times$ choice $\times$ group: all F's $<1.56, \mathrm{NS})$.

\section{Baseline Performance of the Control Task}

Choice behavior, accuracy, and premature responses. When considered as a homogenous group, control animals chose lower-probability/HR trials more than higher-probability/LR trials (Figure $2 \mathrm{~d}$; choice: $\mathrm{F}_{1,17}=41.20, p<0.001$ ). There was no significant difference between the choice behavior of animals yoked to workers (yoked-workers) and those yoked to slackers (yoked-slackers; group: $\mathrm{F}_{1,17}=2.06$, NS). In contrast to rCET animals, control animals showed only a trend to select fewer HR trials at the beginning and ending of the session (quartile: $\mathrm{F}_{3,51}=2.93, p=0.074$; quartile $\times$ group: $\left.F_{3,51}=0.05, \mathrm{NS}\right)$. Animals were nominally more accurate for LR vs HR trials (Figure 2e; choice: $\left.\mathrm{F}_{1,17}=4.56, p=0.048\right)$ although all accuracies fell between 97 and $98.5 \%$ for the control task. There was no difference in accuracy between yoked-workers and yoked-slackers (group: $\mathrm{F}_{1,17}=0.02$, NS). Premature responding was higher during HR trials as compared with LR trials, regardless of animals' yoked groups (Figure $2 \mathrm{f}$; choice: $\mathrm{F}_{1,17}=6.97, p=$ 0.017; choice $\times$ group: $F_{1,17}=0.65$, NS; group: $F_{1,17}=0.01, N S$ )

Other behavioral measures. Lever choice latency and reward collection latency were shorter for HR vs LR trials (choice: all F's $>5.16$, all $p<0.036$; see Supplementary Table S6). All latencies, choice omissions, and completed trials were the same for both yoked-workers and yokedslackers (group/choice $\times$ group: all F's $<1.83, \mathrm{NS}$ ).

\section{Effect of d-Amphetamine Administration on Performance of the Control Task}

Choice behavior, accuracy, and premature responses. Amphetamine dose-dependently decreased choice of HR trials for all control animals, regardless of yoked grouping (Figure $4 \mathrm{a}$; dose: $\mathrm{F}_{3,51}=3.12, p=0.034$; dose-saline $v s$ $1.0 \mathrm{mg} / \mathrm{kg}: \quad \mathrm{F}_{1,17}=4.93, \quad p=0.040 ;$ dose $\times$ group: $\mathrm{F}_{3,51}=$ 1.77, NS). Amphetamine caused a modest but significant
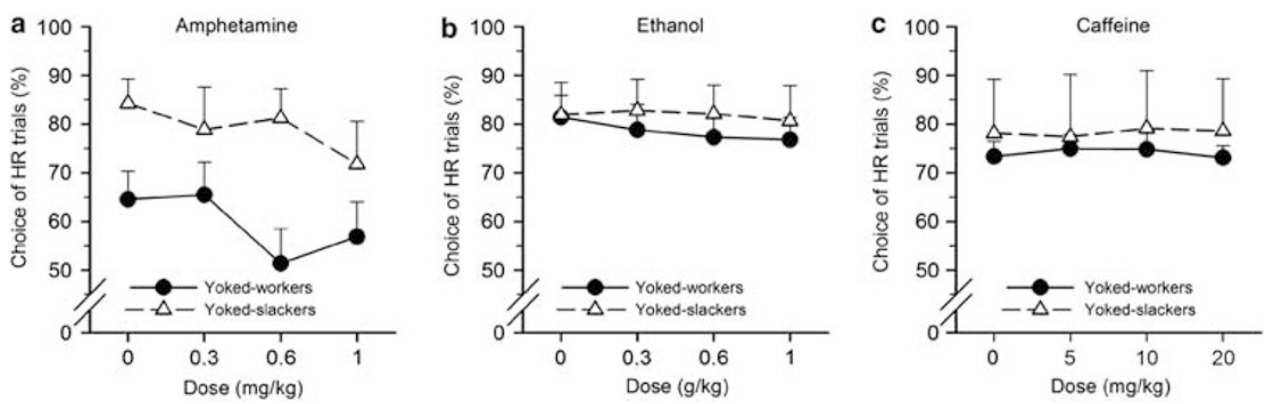

Figure 4 Pharmacological manipulation of choice behavior on the control task. (a) Amphetamine decreased choice of lower-probability/HR trials for all animals on the yoked control task, where effort costs were removed (dose: $p=0.034$; saline vs $1.0 \mathrm{mg} / \mathrm{kg}: p=0.040$ ). (b) Ethanol caused a modest decrease in the choice of HR trials when all control animals were considered together (dose: $p=0.052$; saline vs $1.0 \mathrm{~g} / \mathrm{kg}: p=0.010$ ). (c) Caffeine had no effects on choice in the control task. Data are shown as the mean percent choice for each option ( \pm SEM). 
decrease in accuracy of the control task, from 98 to $95 \%$, but there were no significant group effects (dose: $F_{3,51}=6.92$, $p=0.004 ;$ dose $\times$ group: $F_{3,51}=3.16, \quad p=0.059$; group: $\left.\mathrm{F}_{1,17}=0.04, \mathrm{NS}\right)$. Unsurprisingly, control animals also exhibited a dose-dependent increase in premature responding during amphetamine administration, unrelated to animals' yoked groups (dose: $F_{3,51}=10.90, p<0.001$; dose $\times$ group: $\mathrm{F}_{3,51}=0.20$, NS; group: $\left.\mathrm{F}_{1,17}=0.11, \mathrm{NS}\right)$.

Other behavioral measures. Amphetamine had no effects on response or collection latencies, choice omissions, or completed trials for control animals (all F's $<2.81$, NS; see Supplementary Table S7).

\section{Effect of Ethanol Administration on Performance of the Control Task}

Choice behavior, accuracy, and premature responses. Ethanol tended to reduce choice of HR trials for all control animals, especially at the highest dose (Figure 4b; dose: $\mathrm{F}_{3,51}=2.75, p=0.052$; dose - saline $v s 1.0 \mathrm{~g} / \mathrm{kg}: \mathrm{F}_{1,17}=8.29$, $p=0.010)$. Ethanol had no effects on accuracy and premature responding for control animals and no group interactions were observed for any of the above measures (all F's $<1.55$, NS).

Other behavioral measures. In all animals, ethanol reduced the latency to choose the LR lever but had no effect on the HR option (dose: $F_{3,51}=4.31, p=0.022$; choice $\times$ dose: $\mathrm{F}_{3,51}=4.41, p=0.008$; dose $-\mathrm{LR}$ trials only: $\mathrm{F}_{3,51}=5.42$, $p=0.003$; saline $v s 0.3 \mathrm{~g} / \mathrm{kg}: \mathrm{F}_{1,17}=8.38, p=0.010$; HR trials only: $\mathrm{F}_{3,51}=1.68$, NS; Supplementary Table S8). Ethanol did not affect the correct response latency for control animals (dose: $F_{3,51}=0.72$, NS; choice $\times$ dose: $F_{3,51}=0.71$, NS) but increased the latency to collect reward for all trial types (dose: $F_{3,51}=3.22, p=0.030$; choice $\times$ dose: $F_{3,51}=2.35$, NS). Ethanol did not affect choice omissions (dose: $F_{3,51}=$ 0.95 , NS) but tended to dose-dependently decrease the number of completed trials (dose: $\mathrm{F}_{3,51}=2.65, p=0.059$ ). No interactions with yoked grouping were observed for the above measures (dose $\times$ group/dose $\times$ choice $\times$ group: all F's $<2.41$, NS).

\section{Effect of Caffeine Administration on Performance of the Control Task}

Choice behavior, accuracy, and premature responses. Caffeine had no effects on the choice behavior and accuracy of control animals (Figure 4c; dose/dose $\times$ choice: all F's $<2.19$, NS). Caffeine dose-dependently increased premature responding during both trial types (dose: $\mathrm{F}_{3,51}=3.30$, $p=0.028$; dose $\times$ choice: $\mathrm{F}_{3,51}=3.61, p=0.020$; dose-LR trials only: $\mathrm{F}_{3,51}=2.89, p=0.045$; saline vs $20 \mathrm{mg} / \mathrm{kg}: \mathrm{F}_{1,17}=$ 5.84, $p=0.028$; HR trials only: $\mathrm{F}_{3,51}=4.00,0.013 ;-5 \mathrm{mg} / \mathrm{kg}$ : $\left.\mathrm{F}_{1,16}=7.24, p=0.016 ;-10 \mathrm{mg} / \mathrm{kg}: \mathrm{F}_{1,16}=5.76, p=0.029\right)$. No yoked group interactions were observed (all F's $<0.42$, NS).

Other behavioral measures. Caffeine had no effect on response or collection latencies, choice omissions, or completed trials, and no group interactions were observed (all F's $<2.02$, NS; see Supplementary Table S9).

\section{Effect of Satiation on Performance of the Control Task}

Choice behavior, accuracy, and premature responses. Satiation progressively decreased choice of HR trials across all control animals (Figure 5d; condition: $\mathrm{F}_{2,34}=11.38, p<0.001$; condition $\times$ group: $\mathrm{F}_{2,34}=0.14, \mathrm{NS} ;$ condition-FR $v s$
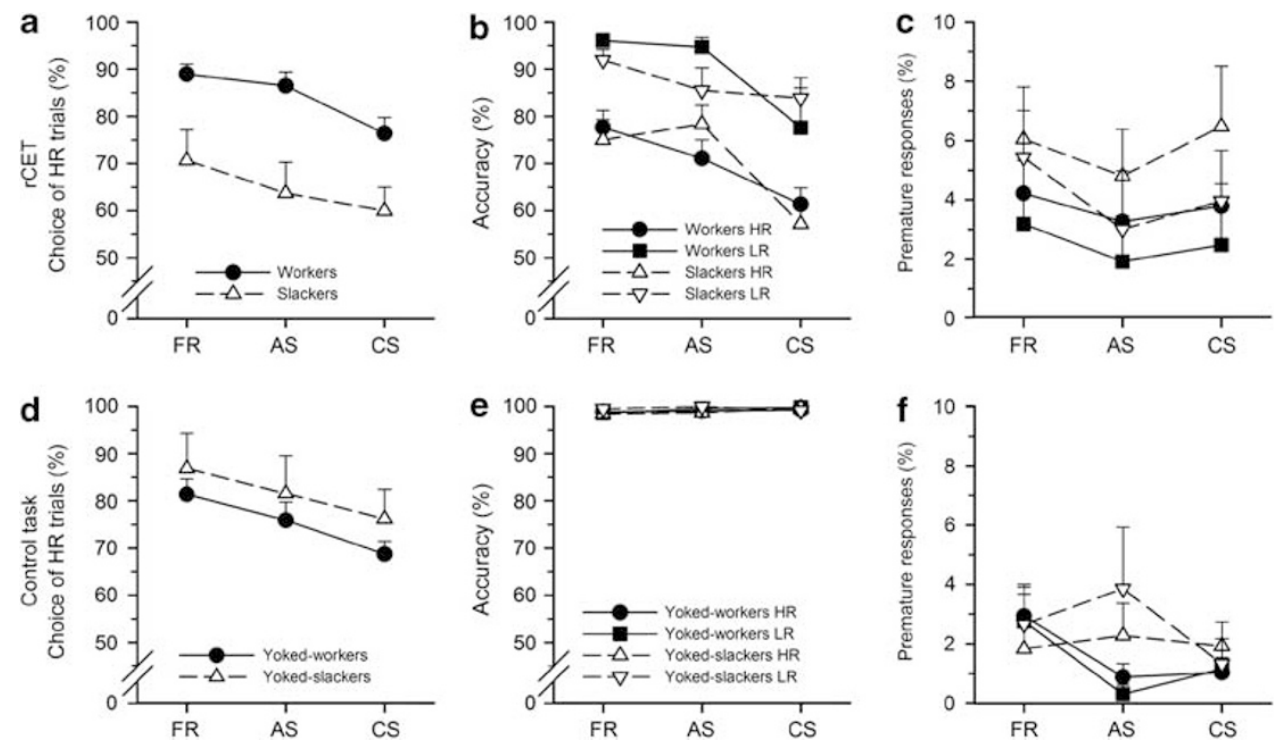

Figure 5 Satiation decreases motivation on the rCET. (a) Satiation (AS and CS) reduced choice of high-effort/HR trials on the rCET, as compared with FR, for both workers and slackers (condition: $p<0.00$ I; FR vs CS: $p<0.00$ I; AS vs CS: $p=0.004$ ). (b) This decrease in choice of HR trials was accompanied by general impairments in accuracy on the rCET (condition: $p<0.00 \mathrm{I}$ ). (c) Motor impulsivity was not affected by satiety. (d) In the control task, where cognitive effort costs were eliminated, all yoked animals also reduced choice of the lower probability HR trials in response to satiation (condition: $p<0.00 \mathrm{I}$ ). (e and f) Satiety had no effect on accuracy or premature responding on the control task. Data are shown as the mean percent choice for each option $( \pm \mathrm{SEM})$. 
AS: $\mathrm{F}_{1,17}=4.76, p=0.044$; FR vs $\mathrm{CS}: \mathrm{F}_{1,17}=17.21, p=0.001$; AS vs CS: $\left.\mathrm{F}_{1,17}=9.42, p=0.007\right)$. Yoked-workers and yokedslackers remained indistinguishable in their choice behavior (group: $\mathrm{F}_{1,17}=2.10, \mathrm{NS}$ ). Satiation had no effect on accuracy or premature responding for control animals (Figure $5 \mathrm{e}$ and $\mathrm{f}$; all F's $<1.57$, NS).

Other behavioral measurements. Satiation increased all response and collection latencies for control animals (condition: all F's $>19.64$, all $p<0.001$; see Supplementary Table S10). Lever choice latency and reward collection latency increased for both LR and HR trials (all F's $>5.41$, all $p<0.020)$. There was also a significant condition by yoked-group interaction for lever choice latency but further analysis showed significant slowing for both yoked-workers and yoked-slackers (condition $\times$ group: $\mathrm{F}_{2,34}=3.81$, $p=0.036$; yoked-workers only: $\mathrm{F}_{2,20}=51.47, \quad p<0.001$; yoked-slackers only: $\left.\mathrm{F}_{2,14}=28.27, p<0.001\right)$. Satiation also increased the number of choice omissions (condition: $\mathrm{F}_{2,34}=24.70, p<0.001$; FR vs AS: $\mathrm{F}_{1,17}=24.37, p<0.001$; FR vs CS: $\left.\mathrm{F}_{1,17}=81.81, p<0.001\right)$ and decreased the number of trials completed by control animals (condition: $F_{2,34}=$ 111.49, $p<0.001$; FR vs AS: $\mathrm{F}_{1,17}=55.56, p<0.001$; FR $v s$ CS: $\mathrm{F}_{1,17}=236.40, \quad p<0.001$; AS $v s$ CS: $\mathrm{F}_{1,17}=52.79$, $p<0.001)$. For all measures except lever choice latency, no yoked group effects or interactions were observed (all F's $<1.83$, NS).

\section{Cognitive Effort vs Control Animals: Comparison of Choice Behavior}

Baseline choice behavior of cognitive effort and control animals was directly compared. There was a significant difference in choice between the two tasks, and a group by task interaction indicated that the worker/slacker distinction did not hold for control animals (task: $\mathrm{F}_{1,34}=5.09$, $p=0.031$; group $\times$ task: $\left.\mathrm{F}_{1,34}=11.78, p=0.002\right)$. There was no difference between the choice behavior of workers and yoked-workers but yoked-slackers chose HR trials significantly more than slackers (task-workers $v s$ yokedworkers: $\mathrm{F}_{1,20}=0.97, \mathrm{NS}$; slackers $v s$ yoked-slackers: $\mathrm{F}_{1,14}=$ $11.43, p=0.004)$. Taken together, these data suggest that the differences between the two tasks (ie, the cognitive effort component) may in part underlie the differences in choice behavior of experimental and control animals.

\section{DISCUSSION}

Here we show for the first time that rats are sensitive to cognitive effort when making decisions. Similar to human subjects (McGuire and Botvinick, 2010), considerable individual variation in choice was observed when rats chose between a cognitively easy, LR trial and a cognitively difficult, HR trial on a cost/benefit decision-making task. 'Workers' chose HR trials significantly more than their 'slacker' counterparts, and these choice preferences also influenced the effects of amphetamine and caffeine: workers 'slacked off' in response to both of these stimulants, whereas slackers 'worked harder' under amphetamine, though not when given caffeine. Baseline individual differences can likewise determine the impact of stimulants on decision- making behavior in human subjects (Anderson and Revelle, 1994; Revelle et al, 1980; White et al, 2007), hence our model could be useful for exploring the biological basis of these drug effects. Finally, we demonstrated that choice of the more difficult option was sensitive to changes in reward value, as satiation decreased choice of HR trials.

Given that the chances of receiving reward on both easy and hard trials varied according to the animals' accuracy, one important consideration was the degree to which effort costs, rather than reward probability, influenced decision making. The performance of a yoked control group demonstrated that choice behavior on the rCET could not be sufficiently explained by probability of reinforcement for LR and HR trials: control animals were yoked to the same reinforcement probabilities as master rats performing the rCET, but their choice preferences were significantly different. In particular, whereas all yoked-workers and yoked-slackers greatly preferred HR to LR trials, slackers chose significantly fewer HR trials than workers on the rCET, despite equal probabilities of reinforcement. Additionally, both amphetamine and ethanol decreased choice of HR trials for all control animals, shifting to the higher probability but lower reward option; in contrast, amphetamine had opposing effects on workers and slackers and ethanol had no effects on choice in the rCET. As the rCET and control tasks differed only in the cognitive effort component (or lack thereof), it is reasonable to infer that animals' behavior on the rCET was critically influenced by the effort costs.

Manipulating satiety levels led to a decrease in choice of $\mathrm{HR}$ trials in all animals. The corresponding increased latencies, decreased accuracy, and decreased number of completed trials suggest that the previously food-restricted animals were less motivated for sugar reward following free access to food. This universal decline in performance has also been observed in animals performing a two-choice reaction task, following their switch from FR to free feeding (Nakamura and Kurasawa, 2001). In animals performing a physical effort discounting task, AS after FR led to decreased choice of HR trials and decreased motor activity (Floresco et al, 2008b), similar to the rCET; however, there was no difference between choice behavior during FR and CS, unlike in the present study. This is likely because of the much greater number of trials completed in the rCET, which may make the task more sensitive to satiety manipulations. Taken together, the satiation data suggest that the performance of the rCET continues to be goal directed even after extensive training, and that the degree to which rats are willing to exert cognitive effort does depend somewhat on the value of the reward for which they are working.

It is worth noting that all experimental and control rats preferred the HR option at baseline, and did not appear to follow strict matching law (Herrnstein, 1970). However, with a mean probability of reinforcement well above chance for HR trials, this was the normatively favorable choice for all animals. It is, therefore, perhaps surprising that slackers chose the low-effort/LR option twice as often as workers on the cognitive effort task. A number of interpretations can be discredited. As slackers and workers exhibited equal accuracy, differences in attentional performance cannot account for the variation in choice. Similarly, the ability to sustain attention across the 30 -min session cannot account 
for differences in choice: slackers did not decrease choice of HR trials across the session, but rather all animals increased their HR choice as the session progressed. Workers and slackers also did not differ in levels of motivation or motor impulsivity, as measured by completed trials or premature responding, respectively. It is also unlikely that slackers failed to understand the consequences of lever/trial-type choice at the beginning of each trial, as slackers demonstrated a higher level of premature responding and shorter response latencies on HR vs LR trials, identical to workers. This pattern of data suggests some anticipation that the SD would be shorter on HR trials, eliciting a more rapid response. Another suggestion is that slackers were indifferent to the variation in reward magnitude between LR and HR trials, but this too is unlikely as slackers collected reward faster following $\mathrm{HR} v s$ LR trials, and were also quicker to do so than workers on HR trials.

Two hypotheses remain that could explain why slackers chose more LR trials than workers. The first is that slackers may be more sensitive to the probability of reward or punishment. On decision-making tasks involving risk or ambiguity, amphetamine challenge has been shown to shift choice preference in favor of smaller rewards delivered with a higher probability, even at a normative cost across the session (Mitchell et al, 2011; Zeeb et al, 2009), in effect increasing animals' sensitivity to reward/punishment probability (but see St Onge et al, 2010). Workers and all control animals demonstrated a similar response to amphetamine, increasing choice of the higher accuracy/probability LR trials. However, slackers shifted their preference away from LR trials following amphetamine administration, demonstrating an increased tolerance to lower probabilities of reinforcement. Therefore, it seems unlikely that slackers are more sensitive to reward/punishment probability at baseline, as arguably amphetamine should then have exacerbated this pattern of choice or perhaps failed to alter decision making in these animals because of a floor effect.

A second interpretation is that slackers may simply be more sensitive to the higher cognitive effort costs that accompany HR trials. This possibility is supported by at least one functional imaging study of humans performing a cognitive switching task (McGuire and Botvinick, 2010), wherein 'high-avoidant' individuals felt a greater subjective cost for the high-effort trials. These individuals also showed greater activation of brain regions related to the effort costs in this task and subsequently chose fewer high-effort trials. Although slackers may experience a greater sense of effort, akin to the high-avoidant participants (McGuire and Botvinick, 2010), it may also be that workers are employing different cognitive strategies to reduce effort costs while maintaining sufficient levels of accuracy (Shah and Oppenheimer, 2008). Moreover, this difference in strategic approach may explain why amphetamine and caffeine caused disparate effects on choice in workers $v s$ slackers, while simultaneously affecting impulsivity and motivation in a similar manner for all animals.

Indeed, the pharmacological manipulations in this study support a dissociation between cognitive effort, visuospatial attention, impulsivity, and motivation for reward. Amphetamine and caffeine increased premature responding, a well-validated measure of impulsive action, while leaving accuracy on the task intact; this parallels previous reports in which amphetamine or caffeine administration increased impulsivity without affecting visuospatial attention on the 5CSRT (Cole and Robbins, 1987; Higgins et al, 2007; Paterson et al, 2011). Similarly, ethanol invigorated behavior on the rCET, as measured by decreased latencies and increased number of completed trials, but did not affect choice behavior; this increased motivation corresponds well with both the effects of ethanol administration reported in a twochoice reaction task (Givens, 1997), and with the lack of effects on accuracy or premature responding using similar doses on the 5CSRT (Bizarro et al, 2003). In the present study's control task, where differences in effort costs were removed, ethanol decreased choice of the lower probability (HR) trials, and this is in line with rats' decreased choice of risky options in a probability-discounting task following ethanol administration (Mitchell et al, 2011). These latter findings support the suggestion that effort and probability discounting may be dissociated at the pharmacological level, a conclusion that is further emphasized by the differential impact of stimulants on the choice behavior of slackers $v s$ yoked-slackers. Altogether, these data demonstrate that the psychomotor effects of these drugs can be separated from their effects on decision making, as has been previously postulated (Floresco et al, 2008b), and that choice based on cognitive effort may be somewhat unique in its neurochemical regulation.

The adenosine receptor antagonist caffeine decreased choice of HR trials in workers but did not affect decision making in slackers or control animals. Adenosine $\mathrm{A}_{2 \mathrm{~A}}$ and dopamine $\mathrm{D}_{2}$ receptors are colocalized within the striatum (Fink et al, 1992) and can have opposing effects on neuronal function (Ongini and Fredholm, 1996), which may in part explain why caffeine and amphetamine displayed some overlapping effects. Although $\mathrm{A}_{2 \mathrm{~A}}$ receptor antagonists have recently been reported to attenuate decrements in physical effort caused by the $\mathrm{D}_{2}$ antagonist haloperidol (Collins et al, 2012), other findings indicated that $A_{2 A}$ agonists have a distinct behavioral profile from $\mathrm{D}_{2}$ antagonists on lever pressing (Jones-Cage et al, 2012). In combination with the unaffected choice behavior of control animals under caffeine, this suggests that caffeine's effects were due to changes in arousal or allocation of attention rather than motivational processes per se. Although striatal $\mathrm{A}_{2 \mathrm{~A}}$ receptors have been implicated in the arousing effects of caffeine (Huang et al, 2005; Lazarus et al, 2011), adenosine $\mathrm{A}_{1}$ and $\mathrm{A}_{2 \mathrm{~A}}$ receptormediated acetylcholine efflux in the cortex may also underlie this arousal (Van Dort et al, 2009). Attentional performance on the 5CSRT is sensitive to cholinergic manipulation (Chudasama et al, 2004; Dalley et al, 2004; McGaughy et al, 2002), and in contrast to amphetamine and caffeine from the present study, acute administration of the acetylcholine agonist nicotine can actually improve performance on the 5CSRT (Bizarro et al, 2004; Stolerman et al, 2009). Furthermore, increases in cortical cholinergic tone accompany sustained attention in rats (Passetti et al, 2000), and effort-reducing strategies decrease this acetylcholine efflux, as measured by microdialysis (Dalley et al, 2001; Himmelheber et al, 2000). At least one human study has demonstrated that caffeine can impair visuospatial orientation whereas leaving other aspects of attention intact (Brunye et al, 2010). As such, caffeine-mediated increases in cortical acetylcholine may have artificially inflated the sense of 
attentional effort in the current task, driving HR-preferring workers toward the easier LR trials while leaving slackers and control animals unaffected.

Differences between the present rCET data and previous physical effort literature also provide evidence that effort may not be a unitary construct. Physical effort studies have highlighted the importance of dopaminergic outputs from the ventral tegmental area in signaling effort costs, and disruptions to midbrain dopamine signaling will shift animals' behavior toward options with lower effort requirements (Cousins et al, 1994; Salamone et al, 2007; Salamone et al, 1994). Conversely, systemic amphetamine $(0.7 \mathrm{mg} / \mathrm{kg})$ increased animals' preference to scale a barrier for greater reward in a T-maze task (Bardgett et al, 2009). Dopaminergic antagonists counteracted these effects, suggesting that amphetamine's actions on this physical effort task were mediated in part via dopamine (Bardgett et al, 2009). Similarly, the general dopamine antagonist flupenthixol shifted animals' choice away from HR trials on the operant effort-discounting task, which requires animals to press the HR lever a greater number of times for a larger reward (Floresco et al, 2008b). However, in contrast to the t-maze task, low doses of amphetamine increased choice of the high-effort option whereas a higher dose $(0.5 \mathrm{mg} / \mathrm{kg})$ decreased choice of HR trials (Floresco et al, 2008b). As to why somewhat divergent effects of amphetamine are observed on the two physical effort paradigms, it is worth noting that disruptions of dopamine exert a greater influence on tasks that have higher physical work requirements (Salamone et al, 2007). As such, the physical costs of scaling a large barrier in a t-maze may be greater than pressing an operant lever multiple times, hence the greater impairments on the maze-based task. Moreover, this could also explain why we found no main effect of amphetamine on choice for the cognitive effort task when the animals were considered as a homogenous sample: the physical effort required for the rCET is very low and equal for LR $v s$ HR trials, and thus minimally affected by dopaminergic manipulations. Consequently, amphetamine's actions on choice behavior in the rCET may not be primarily dopamine dependent, but perhaps because of amphetamine's effect on other catecholamines, acetylcholine, or the downstream targets of these neuromodulators. Experiments designed to explore this proposal are currently underway.

This theme of overlapping-yet-distinct neurochemistry may also extend to neurocircuitry when considering cognitive $v s$ physical effort. A substantial body of literature implicates regions within the cortico-limbic-striatal loop in decision-making based on physical effort requirements, including the nucleus accumbens (Cousins et al, 1996; Salamone et al, 1994), anterior cingulate cortex (Rudebeck et al, 2006; Walton et al, 2003), and basolateral amygdala (Floresco and Ghods-Sharifi, 2007b; Ghods-Sharifi et al, 2009). Lesions or inactivations of these regions shift animals' choice behavior away from high-effort options. Although some functional imaging studies of cognitive effort have shown overlap with these regions (Botvinick et al, 2009), others have shown associations with lateral prefrontal cortex and superior parietal lobule (McGuire and Botvinick, 2010), regions involved in executive control and visuospatial attention, respectively (Cavanna and Trimble, 2006; Miller and Cohen, 2001). A number of studies have also emphasized concurrent or globally synchronized activity across the brain for higher cognitive effort (Barnes et al, 2009; Kitzbichler et al, 2011). From a theoretical perspective, the currency of the costs associated with each task (ie, physical/motor $v s$ cognitive/attentional) may account for some distinct regional activity within the brain. Future experiments will determine whether inactivation of brain regions previously implicated in physical effort likewise effect decisions based on cognitive effort. Furthermore, comparing cognitive $v s$ physical effort choice behavior in the same animal cohort will also help to determine the degree of shared or discrete components in these two forms of effort.

In summary, the data presented here demonstrate that rats can discriminate between two options that vary in the amount of cognitive effort required, and that stable baseline differences are observed in terms of the degree of preference for more effortful trials. This choice behavior can be pharmacologically manipulated without impairing task performance and appears to be independent of other cognitive processes such as impulsivity. Furthermore, drugs may have opposing effects on choice behavior for 'workers' $v s$ 'slackers', perhaps indicating that these two groups are using different strategies when performing the task, which could result in different patterns of neural activation. The rCET may therefore offer insights into the underlying neurobiology of individual differences in effortful choice; in turn, such research may suggest novel therapeutic targets for the many disorders that are associated with impairments in effort-based decision making.

\section{ACKNOWLEDGEMENTS}

This work was supported by an operating grant awarded to CAW from the Canadian Institutes for Health Research (CIHR). CAW also receives salary support through the Michael Smith Foundation for Health Research and the CIHR New Investigator Award program. JGH was supported by the University of British Columbia's University Graduate Fellowship and the Pacific Century Graduate Scholarship.

\section{DISCLOSURE}

CAW has previously consulted for Theravance on an unrelated matter. The other authors declare no conflict of interest.

\section{REFERENCES}

Anderson KJ, Revelle W (1994). Impulsivity and time of day: is rate of change in arousal a function of impulsivity? J Pers Soc Psychol 67: 334-344.

Bardgett ME, Depenbrock M, Downs N, Points M, Green L (2009). Dopamine modulates effort-based decision making in rats. Behav Neurosci 123: 242-251.

Barnes A, Bullmore ET, Suckling J (2009). Endogenous human brain dynamics recover slowly following cognitive effort. PLoS ONE 4: e6626.

Bizarro L, Patel S, Murtagh C, Stolerman IP (2004). Differential effects of psychomotor stimulants on attentional performance in rats: nicotine, amphetamine, caffeine and methylphenidate. Behav Pharmacol 15: 195-206. 
Bizarro L, Patel S, Stolerman IP (2003). Comprehensive deficits in performance of an attentional task produced by co-administering alcohol and nicotine to rats. Drug Alcohol Depend 72: 287-295.

Botvinick MM, Huffstetler S, McGuire JT (2009). Effort discounting in human nucleus accumbens. Cogn Affect Behav Neurosci 9: 16-27.

Brunye TT, Mahoney CR, Lieberman HR, Taylor HA (2010). Caffeine modulates attention network function. Brain Cogn 72: 181-188.

Cardinal RN, Aitken MRF (2006). ANOVA for the Behavioural Sciences Researcher. L Erlbaum: Mahwah, NJ, pp xvi, 448.

Cavanna AE, Trimble MR (2006). The precuneus: a review of its functional anatomy and behavioural correlates. Brain 129(Part 3): 564-583.

Chudasama Y, Dalley JW, Nathwani F, Bouger P, Robbins TW (2004). Cholinergic modulation of visual attention and working memory: dissociable effects of basal forebrain 192-IgG-saporin lesions and intraprefrontal infusions of scopolamine. Learn Mem 11: 78-86.

Chudasama Y, Robbins TW (2006). Functions of frontostriatal systems in cognition: comparative neuropsychopharmacological studies in rats, monkeys and humans. Biol Psychol 73: 19-38.

Cohen RM, Weingartner H, Smallberg SA, Pickar D, Murphy DL (1982). Effort and cognition in depression. Arch Gen Psychiatry 39: 593-597.

Cole BJ, Robbins TW (1987). Amphetamine impairs the discriminative performance of rats with dorsal noradrenergic bundle lesions on a 5-choice serial reaction time task: new evidence for central dopaminergic-noradrenergic interactions. Psychopharmacology (Berl) 91: 458-466.

Collins LE, Sager TN, Sams AG, Pennarola A, Port RG, Shahriari M et al (2012). The novel adenosine $\mathrm{A}(2 \mathrm{~A})$ antagonist Lu AA47070 reverses the motor and motivational effects produced by dopamine D2 receptor blockade. Pharmacol Biochem Behav 100: 498-505.

Cousins MS, Atherton A, Turner L, Salamone JD (1996). Nucleus accumbens dopamine depletions alter relative response allocation in a T-maze cost/benefit task. Behav Brain Res 74: 189-197.

Cousins MS, Wei W, Salamone JD (1994). Pharmacological characterization of performance on a concurrent lever pressing/feeding choice procedure: effects of dopamine antagonist, cholinomimetic, sedative and stimulant drugs. Psychopharmacology (Berl) 116: 529-537.

Croxson PL, Walton ME, O'Reilly JX, Behrens TE, Rushworth MF (2009). Effort-based cost-benefit valuation and the human brain. J Neurosci 29: 4531-4541.

Dalley JW, McGaughy J, O'Connell MT, Cardinal RN, Levita L, Robbins TW (2001). Distinct changes in cortical acetylcholine and noradrenaline efflux during contingent and noncontingent performance of a visual attentional task. J Neurosci 21: 4908-4914.

Dalley JW, Theobald DE, Bouger P, Chudasama Y, Cardinal RN, Robbins TW (2004). Cortical cholinergic function and deficits in visual attentional performance in rats following 192 IgGsaporin-induced lesions of the medial prefrontal cortex. Cereb Cortex 14: 922-932.

de Wit H, Crean J, Richards JB (2000). Effects of d-amphetamine and ethanol on a measure of behavioral inhibition in humans. Behav Neurosci 114: 830-837.

de Wit H, Enggasser JL, Richards JB (2002). Acute administration of d-amphetamine decreases impulsivity in healthy volunteers. Neuropsychopharmacology 27: 813-825.

Drummer OH, Gerostamoulos J, Batziris H, Chu M, Caplehorn JR, Robertson MD et al (2003). The incidence of drugs in drivers killed in Australian road traffic crashes. Forensic Sci Int 134: 154-162.

Egeland J, Johansen SN, Ueland T (2010). Do low-effort learning strategies mediate impaired memory in ADHD? J Learn Disabil 43: $430-440$

Field M, Wiers RW, Christiansen P, Fillmore MT, Verster JC (2010). Acute alcohol effects on inhibitory control and implicit cognition: implications for loss of control over drinking. Alcohol Clin Exp Res 34: 1346-1352.
Fink JS, Weaver DR, Rivkees SA, Peterfreund RA, Pollack AE, Adler EM et al (1992). Molecular cloning of the rat A2 adenosine receptor: selective co-expression with $\mathrm{D} 2$ dopamine receptors in rat striatum. Brain Res Mol Brain Res 14: 186-195.

Floresco SB, Ghods-Sharifi S (2007a). Amygdala-prefrontal cortical circuitry regulates effort-based decision making. Cerebral Cortex 17: 251-260.

Floresco SB, Ghods-Sharifi S (2007b). Amygdala-prefrontal cortical circuitry regulates effort-based decision making. Cereb Cortex 17: $251-260$

Floresco SB, St Onge JR, Ghods-Sharifi S, Winstanley CA (2008a). Cortico-limbic-striatal circuits subserving different forms of costbenefit decision making. Cogn Affect Behav Neurosci 8: 375-389.

Floresco SB, Tse MT, Ghods-Sharifi S (2008b). Dopaminergic and glutamatergic regulation of effort- and delay-based decision making. Neuropsychopharmacology 33: 1966-1979.

Floresco SB, Tse MTL, Ghods-Sharifi S (2008c). Dopaminergic and glutamatergic regulation of effort- and delay-based decision making. Neuropsychopharmacology 33: 1966-1979.

Ghods-Sharifi S, St Onge JR, Floresco SB (2009). Fundamental contribution by the basolateral amygdala to different forms of decision making. J Neurosci 29: 5251-5259.

Givens B (1997). Effect of ethanol on sustained attention in rats. Psychopharmacology (Berl) 129: 135-140.

Gold JI, Shadlen MN (2007). The neural basis of decision making. Annu Rev Neurosci 30: 535-574.

Hammar A, Lund A, Hugdahl K (2003). Selective impairment in effortful information processing in major depression. J Int Neuropsychol Soc 9: 954-959.

Hammar A, Strand M, Ardal G, Schmid M, Lund A, Elliott R (2011). Testing the cognitive effort hypothesis of cognitive impairment in major depression. Nord J Psychiatry 65: 74-80.

Herrnstein RJ (1970). On the law of effect. J Exp Anal Behav 13: 243-266.

Higgins GA, Grzelak ME, Pond AJ, Cohen-Williams ME, Hodgson RA, Varty GB (2007). The effect of caffeine to increase reaction time in the rat during a test of attention is mediated through antagonism of adenosine A2A receptors. Behav Brain Res 185: 32-42.

Himmelheber AM, Sarter M, Bruno JP (2000). Increases in cortical acetylcholine release during sustained attention performance in rats. Brain Res Cogn Brain Res 9: 313-325.

Holdstock L, King AC, de Wit H (2000). Subjective and objective responses to ethanol in moderate/heavy and light social drinkers. Alcohol Clin Exp Res 24: 789-794.

Huang ZL, Qu WM, Eguchi N, Chen JF, Schwarzschild MA, Fredholm BB et al (2005). Adenosine A2A, but not A1, receptors mediate the arousal effect of caffeine. Nat Neurosci 8: 858-859.

Jones-Cage C, Stratford TR, Wirtshafter D (2012). Differential effects of the adenosine A(2A) agonist CGS-21680 and haloperidol on food-reinforced fixed ratio responding in the rat. Psychopharmacology (Berl) 220: 205-213.

Kitzbichler MG, Henson RN, Smith ML, Nathan PJ, Bullmore ET (2011). Cognitive effort drives workspace configuration of human brain functional networks. J Neurosci 31: 8259-8270.

Kool W, McGuire JT, Rosen ZB, Botvinick MM (2010). Decision making and the avoidance of cognitive demand. J Exp Psychol Gen 139: 665-682.

Kurniawan IT, Guitart-Masip M, Dolan RJ (2011). Dopamine and effort-based decision making. Front Neurosci 5: 81.

Lawrie SM, MacHale SM, Power MJ, Goodwin GM (1997). Is the chronic fatigue syndrome best understood as a primary disturbance of the sense of effort? Psychol Med 27: 995-999.

Lazarus M, Shen HY, Cherasse Y, Qu WM, Huang ZL, Bass CE et al (2011). Arousal effect of caffeine depends on adenosine A2A receptors in the shell of the nucleus accumbens. J Neurosci 31: 10067-10075.

McGaughy J, Dalley JW, Morrison CH, Everitt BJ, Robbins TW (2002). Selective behavioral and neurochemical effects of 
cholinergic lesions produced by intrabasalis infusions of 192 IgG-saporin on attentional performance in a five-choice serial reaction time task. J Neurosci 22: 1905-1913.

McGuire JT, Botvinick MM (2010). Prefrontal cortex, cognitive control, and the registration of decision costs. Proc Natl Acad Sci USA 107: 7922-7926.

Miller EK, Cohen JD (2001). An integrative theory of prefrontal cortex function. Annu Rev Neurosci 24: 167-202.

Mitchell MR, Vokes CM, Blankenship AL, Simon NW, Setlow B (2011). Effects of acute administration of nicotine, amphetamine, diazepam, morphine, and ethanol on risky decision-making in rats. Psychopharmacology (Berl) 218: 703-712.

Mukherjee S, Yadav R, Yung I, Zajdel DP, Oken BS (2011). Sensitivity to mental effort and test-retest reliability of heart rate variability measures in healthy seniors. Clin Neurophysiol 122: 2059-2066.

Naccache L, Dehaene S, Cohen L, Habert MO, Guichart-Gomez E, Galanaud D et al (2005). Effortless control: executive attention and conscious feeling of mental effort are dissociable. Neuropsychologia 43: 1318-1328.

Nakamura K, Kurasawa M (2001). Aniracetam restores motivation reduced by satiation in a choice reaction task in aged rats. Pharmacol Biochem Behav 68: 65-69.

Ongini E, Fredholm BB (1996). Pharmacology of adenosine A2A receptors. Trends Pharmacol Sci 17: 364-372.

Passetti F, Dalley JW, O'Connell MT, Everitt BJ, Robbins TW (2000). Increased acetylcholine release in the rat medial prefrontal cortex during performance of a visual attentional task. Eur J Neurosci 12: 3051-3058.

Paterson NE, Ricciardi J, Wetzler C, Hanania T (2011). Sub-optimal performance in the 5-choice serial reaction time task in rats was sensitive to methylphenidate, atomoxetine and d-amphetamine, but unaffected by the COMT inhibitor tolcapone. Neurosci Res 69: 41-50.

Peeling P, Dawson B (2007). Influence of caffeine ingestion on perceived mood states, concentration, and arousal levels during a 75-min university lecture. Adv Physiol Educ 31: 332-335.

Revelle W, Humphreys MS, Simon L, Gilliland K (1980). The interactive effect of personality, time of day, and caffeine: a test of the arousal model. J Exp Psychol Gen 109: 1-31.

Robbins TW (2002). The 5-choice serial reaction time task: behavioural pharmacology and functional neurochemistry. Psychopharmacology (Berl) 163: 362-380.

Rudebeck PH, Walton ME, Smyth AN, Bannerman DM, Rushworth MFS (2006). Separate neural pathways process different decision costs. Nat Neurosci 9: 1161-1168.

Rushworth MF, Noonan MP, Boorman ED, Walton ME, Behrens TE (2011). Frontal cortex and reward-guided learning and decision-making. Neuron 70: 1054-1069.

Salamone JD, Correa M, Farrar A, Mingote SM (2007). Effortrelated functions of nucleus accumbens dopamine and associated forebrain circuits. Psychopharmacology (Berl) 191: 461-482.

Salamone JD, Cousins MS, Bucher S (1994). Anhedonia or anergia? Effects of haloperidol and nucleus accumbens dopamine depletion on instrumental response selection in a T-maze cost/ benefit procedure. Behav Brain Res 65: 221-229.

Shah AK, Oppenheimer DM (2008). Heuristics made easy: an effort-reduction framework. Psychol Bull 134: 207-222.

Shalev A, Bleich A, Ursano RJ (1990). Posttraumatic stress disorder: somatic comorbidity and effort tolerance. Psychosomatics 31: 197-203.

Silber BY, Croft RJ, Papafotiou K, Stough C (2006). The acute effects of d-amphetamine and methamphetamine on attention and psychomotor performance. Psychopharmacology (Berl) 187: 154-169.
Smit AS, Eling PA, Coenen AM (2004). Mental effort causes vigilance decrease due to resource depletion. Acta Psychol (Amst) 115: 35-42.

St Onge JR, Chiu YC, Floresco SB (2010). Differential effects of dopaminergic manipulations on risky choice. Psychopharmacology (Berl) 211: 209-221.

Stolerman IP, Naylor CG, Mesdaghinia A, Morris HV (2009). The duration of nicotine-induced attentional enhancement in the five-choice serial reaction time task: lack of long-lasting cognitive improvement. Behav Pharmacol 20: 742-754.

Stulemeijer M, Andriessen TM, Brauer JM, Vos PE, Van Der Werf S (2007). Cognitive performance after mild traumatic brain injury: the impact of poor effort on test results and its relation to distress, personality and litigation. Brain Inj 21: 309-318.

Stulemeijer M, van der Werf S, Bleijenberg G, Biert J, Brauer J, Vos PE (2006). Recovery from mild traumatic brain injury: a focus on fatigue. J Neurol 253: 1041-1047.

Sun H, Cocker PJ, Zeeb FD, Winstanley CA (2012). Chronic atomoxetine treatment during adolescence decreases impulsive choice, but not impulsive action, in adult rats and alters markers of synaptic plasticity in the orbitofrontal cortex. Psychopharmacology (Berl) 219: 285-301.

Treadway MT, Buckholtz JW, Schwartzman AN, Lambert WE, Zald DH (2009). Worth the 'EefRT'? The Effort Expenditure for Rewards Task as an Objective Measure of Motivation and Anhedonia. PLoS ONE 4: e6598.

Van Dort CJ, Baghdoyan HA, Lydic R (2009). Adenosine A(1) and $\mathrm{A}(2 \mathrm{~A})$ receptors in mouse prefrontal cortex modulate acetylcholine release and behavioral arousal. J Neurosci 29: 871-881.

Wallman KE, Sacco P (2007). Sense of effort during a fatiguing exercise protocol in chronic fatigue syndrome. Res Sports Med 15: 47-59.

Walton ME, Bannerman DM, Alterescu K, Rushworth MFS (2003). Functional specialization within medial frontal cortex of the anterior cingulate for evaluating effort-related decisions. I Neurosci 23: 6475-6479.

White TL, Lejuez CW, de Wit H (2007). Personality and gender differences in effects of d-amphetamine on risk taking. Exp Clin Psychopharmacol 15: 599-609.

Winstanley CA (2011). The utility of rat models of impulsivity in developing pharmacotherapies for impulse control disorders. $\mathrm{Br}$ J Pharmacol 164: 1301-1321.

Winstanley CA, Chudasama Y, Dalley JW, Theobald DE, Glennon JC, Robbins TW (2003). Intra-prefrontal 8-OH-DPAT and M100907 improve visuospatial attention and decrease impulsivity on the five-choice serial reaction time task in rats. Psychopharmacology (Berl) 167: 304-314.

Winstanley CA, Zeeb FD, Bedard A, Fu K, Lai B, Steele C et al (2010). Dopaminergic modulation of the orbitofrontal cortex affects attention, motivation and impulsive responding in rats performing the five-choice serial reaction time task. Behav Brain Res 210: 263-272.

Wright RA, Martin RE, Bland JL (2003). Energy resource depletion, task difficulty, and cardiovascular response to a mental arithmetic challenge. Psychophysiology 40: 98-105.

Wright RA, Stewart CC, Barnett BR (2008). Mental fatigue influence on effort-related cardiovascular response: extension across the regulatory (inhibitory)/non-regulatory performance dimension. Int J Psychophysiol 69: 127-133.

Zeeb FD, Robbins TW, Winstanley CA (2009). Serotonergic and dopaminergic modulation of gambling behavior as assessed using a novel rat gambling task. Neuropsychopharmacology 34: 2329-2343.

Supplementary Information accompanies the paper on the Neuropsychopharmacology website (http://www.nature.com/npp) 